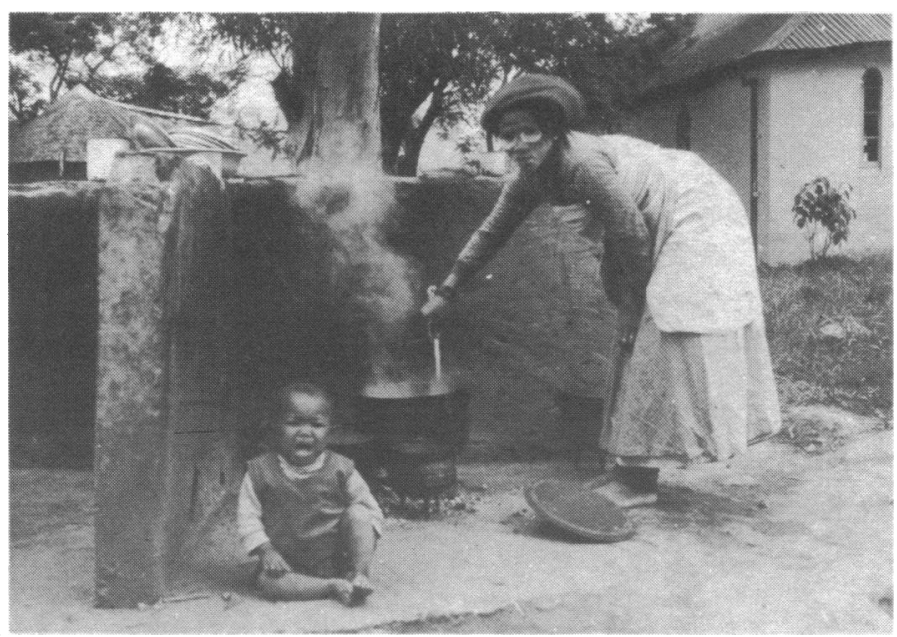

Preparing a balanced midday meal of samp, beans, and vegetable soup.

\section{Hope for the future}

No-amen is 23 years old. Of her five pregnancies, two ended in miscarriage and one in stillbirth. No-caesar was a transverse lie born by caesarean section. If No-amen doesn't learn about nutrition soon Fikile may die. Infant mortality is about $30 \%$ here. Tuberculosis waits around every corner to invade those ill equipped to deal swiftly with it. Measles is a killer in the malnourished child. No-caesar may follow suit if No-amen doesn't learn the prevention and treatment of kwashiorkor.

No-amen may make a good pupil. When she returns to her own village she may be able to diagnose kwashiorkor in her neighbours' children and pass on the dietary advice and agricultural experience she gained at Kwazup. Without such a nutritional rehabilitation unit as Kwazup, Fikile would have been admitted to hospital. In some centres, because of overcrowding No-amen would have been sent home. She would be recalled a month or so later to collect a healthier looking Fikile but would be none the wiser about the cause of his problem. And what would happen to her other children?

In other centres she would have been admitted to help with Fikile's nursing care. Health education would have been given for an hour or so daily by an unfamiliar nurse in unfamiliar surroundings, personal attention being impossible.

Without the help of units such as Kwazup kwashiorkor will continue. Hence for me, Kwazup symbolises a realistic approach to primary health care in a developing country.

(Accepted 3 fune 1980)

\title{
Bold statues on the BMA building
}

\author{
J R HERON
}

"We are concerned most of all with the effect the figures will produce on the minds of the young people."1

"I do not know the sculptor, but I hear he is a young man. From the works I have seen I believe the British Medical Association will be proud of having given him this work to do in the future when he has made the name for himself which his work promises.

"PS. May I add that I think the work is too severe and reverent to be in any way improper?"?

Jacob Epstein was born 100 years ago, in 1880 in East Side, New York. He completed his public schooling at the age of 13, and then worked for a time as an instructor in a boys' gymnasium and as a farm labourer; his abiding ambition was to be an artist. His first poor studio in Hester Street, New York, was burnt to the ground. This chance event in a curious way foreshadows the indiscriminate relationship that was to exist between Jacob Epstein and the realisation of his artistic destiny.

He came to study sculpture in Paris in 1902 at the École des Beaux Arts and later at the Julian Academy. He was a rebellious and impatient student and after an unsettled period in France came to London in 1905. In the light of an undeserved reputation for temperamental wildness, it was perhaps surprising that he should be approached by Mr Charles Holden, the architect, to

\footnotetext{
Department of Neurology, North Staffordshire Royal Infirmary, Stoke-on-Trent ST4 7LN

J R HERON, MB, FRCP, consultant neurologist
}

decorate the buildings of the new British Medical Association in the Strand in 1908. This simple and welcome commission was to prove costly to the artist and led to a controversy which Epstein has referred to as the 30 years' war.

\section{Battle engaged}

Epstein began his task, which was to represent symbolically in 윽 18 larger than life-size figures the life of man and woman from $N$ birth to old age. In 14 months of furious activity he depicted in $D$ symbolic stone archetypal subjects including primal energy, matter, hygeia, chemical research, academic research, mentality, $\tilde{N}$ youth, man, puberty, and, in the Strand mother and child, the N first unsentimental portrayal of motherhood in sculpture since the Renaissance. He characteristically rejected an earlier suggestion from the BMA that the figures should be of historically famous medical men.

The controversy that surrounded these statues stemmed from their nudity or near-nudity and the fact that they would be visible to the man in the street at the corner of Agar Street and the Strand, even allowing that they were perched high on a parapet and for accurate detail to be appreciated would require the use of an "optical telescope."

The Evening Standard and St fames Gazette opened a 8 vendetta on 19 June 1908 when hoardings were removed from around the building, which allowed four of the statues to be 흘 clearly viewed from the street. The newspaper launched a bitter $\stackrel{F}{\rightleftharpoons}$ and outraged objection to the statues, philistine in its morality and concerned above all with the effect that the figures might 


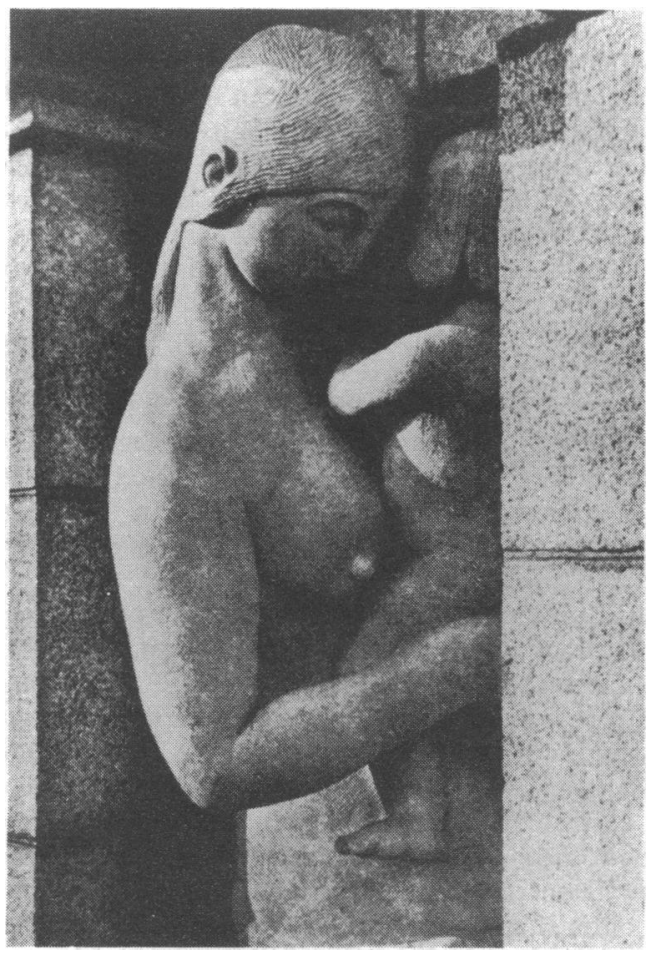

(1)

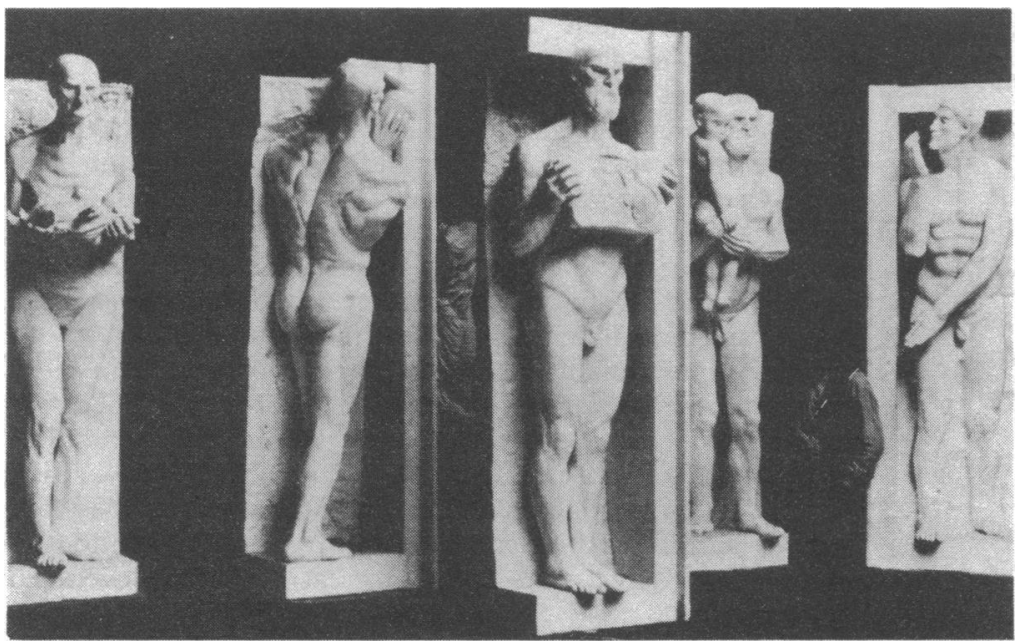

(3)

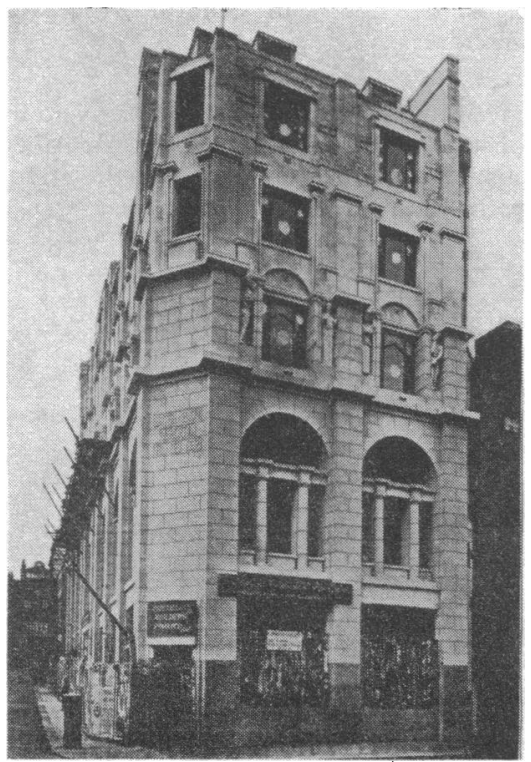

(2)

(6)
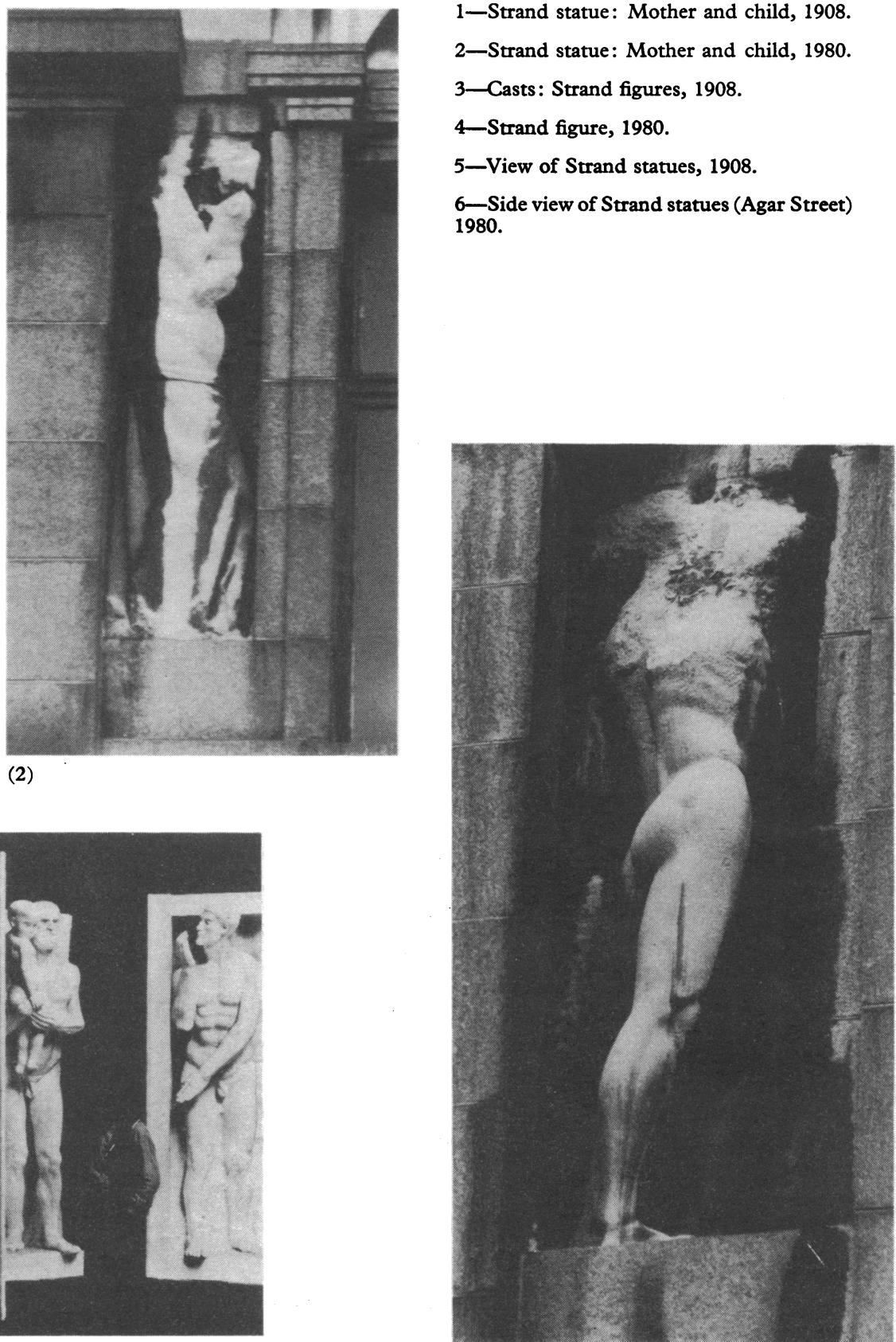

(4)

2-Strand statue: Mother and child, 1980.

3-Casts: Strand figures, 1908.

4-Strand figure, 1980.

5-View of Strand statues, 1908.

6-Side view of Strand statues (Agar Street) 1980.

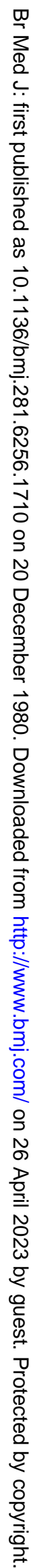

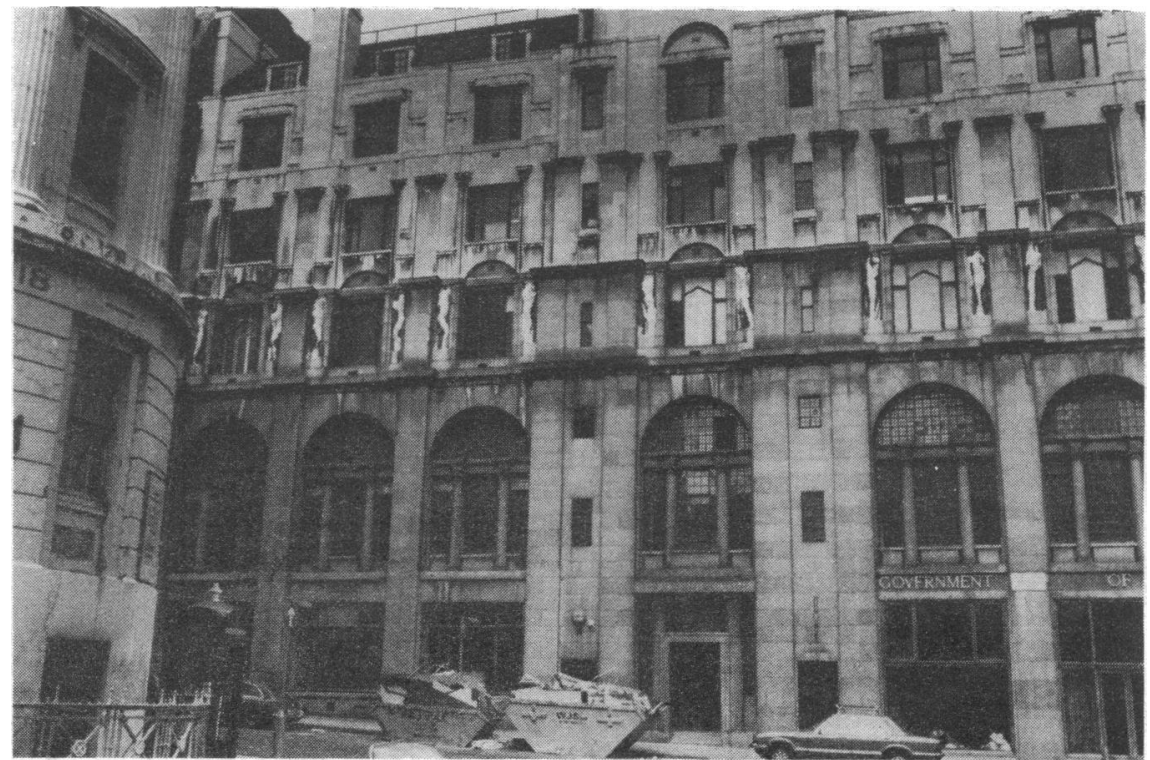


produce in corrupting the minds of young people. The BMA was exhorted to modify its plans and to stop the commission. Scotland Yard was alerted, and an appeal was made to the London County Council. The Evening Standard had successfully engineered the ingredients for an editorial "scoop." The National Vigilance Society, who regarded the matter as scandalous, lodged a protest with the Secretary of the BMA, although Dr Cosmo-Lang, then Bishop of Stepney, later to be Archbishop of Canterbury, found "nothing indecent or shocking on close inspection." C J Holmes, Slade Professor of Fine Arts, Charles Ricketts, Laurence Binyon, and several other artists wrote persuasively in Epstein's defence. Correspondence followed in The Times and in the British Medical fournal. On $1 \mathrm{July}$, at a committee meeting of the BMA in private session, Mr Edmund Owen, FRCS, in the chair, the fate of the statues was discussed. The committee asked Sir Charles Holroyd, director of the National Gallery, to furnish them with an opinion on the indecency or otherwise of the statuary. Sir Charles replied that he thought the BMA would be proud of having given Epstein this work to do. At a later meeting of the BMA it was resolved to instruct the architect to proceed with the work. This might have been the end of the story and the statues forgotten by all except those who scan the skyline of a city with artistic sensibility. Such an outcome might then have reflected proper credit on the BMA for its generous patronage, mature judgment, and prudent investment; this was not to be.

\section{Battle lost}

In 1935 the Government of Southern Rhodesia acquired the BMA building and it was quickly announced that the statues were to be removed as undesirable. Epstein was naturally insulted and wrote to the Observer on 5 May 1935, stating that the figures were intended to have a universal appeal, even perhaps understood in South Rhodesia. He pointed out that neither he nor Mr Charles Holden had been consulted and that the statues were an integral part of the building, and to remove them would damage the statues. He concluded his letter, "ownership does not give the right to remove, and destroy or even the right to sell." The battle between David and Goliath was resumed.

Rhodesia House shifted its ground and in the end was prepared to admit that the figures might be appropriate around the BMA building but were quite out of place for a government office. "Anatomy for the British Medical Association-Yes, but do these figures indicate the produce of South Rhodesia ?-No." Once again men of sound artistic judgment rallied to Epstein's support. Sickert wrote to the Daily Telegraph and important support also came from Kenneth Clark and from Eric Maclaggen, director of the Victoria and Albert Museum. Richard Sickert also indignantly resigned his membership of the Royal Academy because its president, Sir William Llewellyn, would not add his signature to a letter to The Times (10 May) defending Epstein's statues against this act of "vandalism" proposed by the Government of Southern Rhodesia. Under a barrage of enlightened pressure the statues were saved for a further two years.

The ironic end of the tragedy was that after the coronation of King George VI, following the removal of decorative bunting that had been attached to the statues, a small portion of the statuary fell. This was manna from heaven to Rhodesia House. Epstein was refused permission to examine the statues or to report on the state of the statues, which he believed were prematurely eroded by chemical substances released from protective metal cornices set above the statues. The Rhodesian Government would not allow adequate casts to be taken, and to this day we lack good photographic representation of the statues as they were in their original form. The vandals prevailed and the statues were "demolished." In Epstein's words, "the battle was lost ... anyone passing along the Strand can now see as on some antique building the few mutilated fragments of my decoration."

\section{Further criticism}

In company with many other artists Epstein suffered from much unjust and ignorant criticism throughout his life; his tomb for Oscar Wilde in the cemetery of Père Lachaise was for a time covered by tarpaulin and guarded by a gendarme, and a bronze plaque was fixed over the sexual organs of the angel in this work. In 1924 the monument to W H Hudson in Hyde Park was grossly censured-the Daily Mail wrote, "Take this horror out of the park," and the Morning Post, "Were not the English a tolerant people it [the monument] would long ago have been broken in pieces." When, in 1928, Charles Holden once again bravely commissioned Epstein to decorate the London Transport Headquarters, the monumental sculpts "Day and Night" were publicly denounced. Epstein's "Genesis" was vilified in 1930 and referred to as "Epstein's latest and his worst" in the Daily Mail, as "a statue unfit to show" in the Daily Telegraph, and "O you white foulness" in the Daily Express.

It is difficult to understand the extent of the outcry against Epstein's Strand statues in 1908. They were bold statues, it is true, but very much in the classical idiom of Donatello, Michelangelo, and Rodin. It is even more difficult to comprehend how such an attitude should prevail into the mid-'thirties and harden into the wantonness of the decision taken by the Rhodesian Government to destroy the statues. Anger and prejudice are common reactions to new ideas and to new art. Such a reaction is not purely or characteristically English. The French artist Monet, 40 years older than Epstein, was still at this time victim to rancour and public misunderstanding of his paintings. He too had his champions, for Zola appraised him as "A man amidst this crowd of eunuchs." Audiences in Paris, which was then a centre of world culture, were soon to riot over Stravinski's virile but unacceptably modern music, "Rite of Spring." Edwardian society had not recovered sufficiently from the artistic excesses of the Victorian Age, when the great Ruskin had libelled Whistler as "a cock's comb ... flinging a pot of paint in the public's face," for which Whistler was awarded one farthing's damages in the Court of the Exchange Division in 1878. The social affront of Oscar Wilde still lay heavily and ambivalently on the conscience of the middle classes. Morality and aesthetics have always been uncomfortable bedfellows.

Today, the remnants of the "lost" Strand statues are recognisable in form, severely mutilated, like torsos exhumed from another age or culture. Rhodesia House is empty, Epstein is dead, Southern Rhodesia has changed to Zimbabwe, BMA House is in Tavistock Square. The outside of the Strand building is to be cleaned, and the Rhodesia crest with its Latin motto "Sic nomine digna" (Let us deserve to be great) will be removed. The rest is silence.

"Apart from my desire to decorate a beautiful building, I wished to create noble and heroic forms to embody in sculpture, the great primal facts of man and woman."”

I am grateful for the help given by Arup Associates, London and for their kind permission to publish photographs. I also thank Mr Albert Harper of Zimbabwe Pensions Office for granting access to the Strand premises to examine the present state of the Epstein statues.

\section{References}

1 Evening Standard and St Fames Gazette 190819 June.

2 Holroyd C. Br Med f 1908; 4 July:43.

3 Epstein J. Br Med f 1908; 4 July:40.

\section{Bibliography}

Buckle R. Facob Epstein: sculptor. London: Faber \& Faber, 1963. Epstein J. An autobiography. London: Hulton Press, 1955.

(Accepted 29 October 1980) 